DOI: https://doi.org/10.24297/jaa.v10i0.8442

\title{
Effect Of Surfactant Compound Sprays on the Rate of Adsorption on Different Target Surfaces
}

\author{
Muhammed Cemal Toraman ${ }^{a}$, Ali Bayat ${ }^{b}$

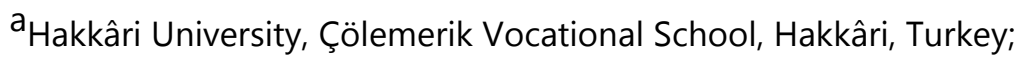 \\ ${ }^{\mathrm{b}}$ Çukurova University Department of Agricultural Machinery and Technology Engineering, Adana, Turkey \\ cemaltoraman@hakkari.edu.tr
}

\begin{abstract}
The first operation of adsorption on leaf surfaces in pulverization is drop sticking. In the water wettability of the surfaces, the sticking of the drops has a great importance. Drop contact angle, contact height, and contact diameter values in the third and tenth seconds were measured with Drop Shape Analysis 10 device to determine adsorption, spreading, and sticking levels by applying mixtures of ten surface active substances including different contents with pure water to different leaf surfaces. The adsorption and sticking rates of the drops they formed on different leaf surfaces were determined for the time they are obtained from the data obtained in both time periods. Furthermore, the spreading rates of the mixtures prepared by taking into account the change rates during the last seven seconds between these two periods were determined as the sticking rate. Coating shares related to covering rates of different surface active substances with different surface properties on the surface of leaves were evaluated as possible work success according to the adsorption, spreading and sticking levels anticipated in spraying. According to their results on the application surfaces, surface active substances and leaves were evaluated statistically by the SPSS 15 program in terms of their similar properties. It has been found that surface active substance mixtures with sodium carboxymethylcellulose and carboxymethylcellulose contents had the largest drop contact angles and contact heights with the smallest drop contact diameters on the leaf surfaces, and a negative impact on the adsorption performance as they spread very little over seven seconds. It has been determined that drops with surface active substance including trisiloxane + allyloxypolyethyleneglycol and alcoholethoxylate, alkylphenolethoxylate have formed the smallest contact angles, minimum drop heights and largest contact diameters on the surface of the leaves, as well as increased adsorption and sticking by spreading rapidly for seven seconds.
\end{abstract}

Keywords: Clinging To; Contact Diameter; Drop Heights; Leaves

\section{Introduction}

In characterizing the properties of different surfaces, the use of contact angle data on these surfaces of drops formed with different liquids is common. However, the determination of the contact heights of the drops on the surface and the change in the time, and the determination of the contact diameters of the drops formed on the contact surfaces and the examination of the change rates with time can give results that will make the surface characterization meaningful. The pulverization performance in the application of pesticides is increased by the additives added to the spraying liquid.

The goal in a pulverization is to break up the liquid into drops, to transport the drops to the target, to deposit the drops onto the target surface, and to provide a high level of biological activity [1].

The area covered by the pulverization drop on the surface deposited depends on the diameter of the drop, the surface tension and the properties of the leaf surface [2].

When a drop is applied to leaf surface, this drop either adsorbs to the surface or splashes back, splits, is reshaped, 
spreads, or flows. The total amount of spray held by the leaf can be quite different from the sticking amount of initially sprayed drops. The amount of adsorption is also affected by the surface and structure of the leaf.

In order to be able to say that a surface is wettable, the contacting liquid must spread to the surface in such a way that it does not form a drop. The contact angle of the drop on the solid surface is used to define the relative grade of the interaction of the liquid with the solid surface $[3,4,5,6]$. Drop contact angle tests are implemented as a simple method to measure the wettability of different plant species [7].

The surface active substance is used to help drops to spread over a larger area and adsorb better on the leaf by reducing the surface tension effect of the liquid. Surface active substances increase adsorption of drops on plant surfaces by reducing surface tension $[8,9]$.

as discussed elsewhere $[10,11,12,13,14]$, By addition of surface active substances, small drops are determined to be more effectively held and spread than large drops. When surface active substances are used, it has been reported that intake of pesticides from the drops to the leaves and the biological activity of the active ingredients are improved. as discussed elsewhere $[15,16,17,18]$, It has also been reported that the dimensions of spray drops have been changed by surface active substances.

as discussed elsewhere $[19,20]$, Organosilicon surface tension reducers have been reported to increase the spread and adhesion (wetting) of the application of pesticides to leaf surfaces due to their high surface activity.

As discussed elsewhere [21,22], It is found that non-ionic surface tension reducers improved the accumulation, adsorption, drop covering amount and sticking on the leaves when they were added to spray mixtures.

As discussed elsewhere [23], it has been stated that the first treatment of the adsorption of the spray liquid is the drop sticking. At the wettability of the surfaces with water, the sticking of the drops at the beginning has a great effect.

\section{The Purpose and Importance of the Study}

In determining the activities of pesticides, evaluations are made according to the contact angles of the drops applied to the target surface at any time obtained by the two-dimensional image processing devices. This approach, where incomplete and sometimes erroneous results are obtained, is believed to be useful in achieving more realistic results with contact angle measurements and contact diameters, and evaluations combined with contact height data at least until the use of three-dimensional image processing devices has begun. In this study, it has been tried to determine the potentials of the target leaf surfaces and the physicochemical properties of the spray to affect the applications of pesticides over time. For this purpose, the interaction levels between leaf surfaces and surface active substances were investigated by observing changes over time in contact angles, contact heights and contact diameter values of drops formed from the mixtures in determining the spreading and adhesiveness properties written on surface active substances sold in the market.

\section{Materials and methods}

Surface active substances used in the studies are given in Table 1 by their product nomenclature codes instead of trade names so that the results obtained do not affect any legal consequences. Five of them are Anionic and others have a Non-ionic chemical structure. Application concentrations of surface active substances are ranged in 0.2-1 mL.L ${ }^{-1}$.Drop Shape Analysis 10 (DSA 10) manufactured by Krüss company was used in determining the values such as the surface tension and the drop contact angles, the drop contact height, the contact diameter and the covering rate of spreader adhesives used in the research 
Table 1. Effective materials, label doses and ion constructions of surface active substances used in experiments

\begin{tabular}{llll}
\hline Product & Effective Substance Concentration ${ }^{1}\left[\mathrm{~mL} \mathrm{~L}^{-1}\right]$ & & Structure \\
\hline A & Fatty asit ve polialkol & 2,5 & Aniyonik \\
B & Sodiumcarboxilmetylcelulos & 0,3 & Aniyonik \\
C & Sodiumcarboxilmetylcelulos & 0,5 & Aniyonik \\
D & Resin & 1 & Noniyonik \\
E & Sodyum dikotil sülfosuksinat & 0,5 & Aniyonik \\
F & Trisiloxane alkoxylates & 0,4 & Noniyonik \\
G & Polyalkaleneoxide-heptamethylTrisiloxane, & 0,2 & Noniyonik \\
& Allyloxypolyethyleneglycol & & Aniyonik \\
H & Carboxymethylcelluse & 1 & Noniyonik \\
I & Alcohol ethoxylate, alkylphenol ethoxylate & 1 & Noniyonik \\
J & Alkilpoliglikoleter & 0,5 & \\
\hline
\end{tabular}

${ }^{1}$ Concentration with pure water according to label value

The surface tensions of ten surface active substances studied were determined after mixing with pure water according to their label values. Each of the mixtures was applied ten times to find the contact angles on different leaf surfaces for determining their behaviours on seven different leaf surfaces. Values such as contact angles, covering areas, drop contactheight, contact diameter data of drops formed are recorded for the third and tenth seconds, and the experiments were carried out accordingly. Depending on the drop height and the drop diameter results created by the drops on the surface within three seconds, evaluations were made as to adsorb the leaf surfaces or to flow over the surfaces. For seven seconds between the third and tenth seconds, the amounts of spreading and sticking were determined from the contact angles and covering rates of the drops adsorbed to the leaf surface.

The contact heights of the liquids dropped on the leaf surfaces were primarily determined for the third second. The same operations were performed for the tenth second, and the average of the changes in height values between the two times was determined. Changes in the ability to stick have been obtained by examining the amount of decrease in height over the elapsed period of seven seconds as the rate of spreading of drops on the surface.

İn the determination of the effectiveness of the prepared mixtures, the change in contact diameters over time on the leaf surfaces was evaluated as the spreading properties of different leaf surfaces. By making the necessary analyses, coating shares related to covering rates of different surface active substances with different surface properties on the surfaces were evaluated as possible work success according to the spreading and sticking levels anticipated in spraying. It was tried to determine the similar properties of the surface active substance mixtures according to the results they formed on the application surfaces, and having evaluated the obtained results in terms of these properties, necessary groupings were made. 


\section{Evaluation of data}

All observational results obtained in this study were conducted with version 15 of the SPSS statistical program. In comparison of the obtained results, Kolmogorov-Smirnov test was applied to determine the normal distribution of the parameters to be analysed and it was determined that the data showed normal distribution. One-way variance analysis by making homogeneity tests of the data. It was performed for $95 \%$ confidence interval according to the Tukey comparison test.

\section{Results}

\section{Surface tensions of mixtures prepared with surfactants}

It has been determined in Table 2 that surface tensions of surfactants have very close values to each other and show little change. Among them, the largest surface tension belongs to the $C$ additive substance and the lowest surface tension belongs to the E surface active substance. However, it has been observed that their solutions, which were prepared by diluting the additives with pure water according to the recommendations on the labels on their packages, increased the surface tension values of most of them. The surface tension values of $\mathrm{H}$ and $\mathrm{C}$ adjuvants were found to be at pure water surface tension level. It is understood that the mixtures formed with these two surfactants do not lower the surface tension values, i.e. they do not affect the physical properties of the water used as the carrier, nor do they change the factors that affect the formation of the drop. It has been reported in their labels that the adjuvants $\mathrm{B}, \mathrm{C}$ and $\mathrm{H}$ given in Table 1 consist of carboxymethylcellulose and sodium carboxymethylcellulose components. It can be said that this ineffectiveness is mainly due to the cellulose derivative properties of products $B, C$ and $H$. At surface tensions of mixtures prepared at $0.3,0.5$ and $1 \mathrm{~mL} . \mathrm{L}^{-1}$ rates respectively with these additives of cellulose derivative, it was observed that there was an increase rather than a decrease depending on the increasing concentration. This result is consistent with the knowledge that cellulosic additives are used as viscosity and texture promoter [24]. It has been reported that the product I, whose effective substances are alcoholethoxylate and alkylphenol ethoxylate, has been used for many years as a good cleaner among surface tension reducers in the cleaning industry as well as in many sectors. However, it is also recommended some alkylphenol ethoxylates are toxic to fish, birds and mammals, and alternative surface tension reducers should be used [25]. Generally, when Table 2 is evaluated, it is observed that non-ionic surface active substances have higher surface tension than anionic additives. It has been determined that the product A, which contains Fatty acid and polyalcohol compound in its anionic additives, reduced the surface tension of the resulting mixture most. It has been reported that the fatty acids assessed in biological surface active substances reduce water surface tension from $72 \mathrm{mN} \mathrm{m}^{-1}$ to $27 \mathrm{mN} \mathrm{m}^{-1}$ [26, 27]. In their research, they reported that the surface tension of water and alcohol mixtures was around $20 \mathrm{mN} \mathrm{m}^{-1}$ at different concentrations and due to different measurement methods. E surfactant having the lowest surface tension in the second order with $49,24 \mathrm{mN} \mathrm{m}^{-1}$ within anionic additives consists of sodium dioctyl sulfosuccinate composition. Surface tension reducers with the active ingredient Sodium dioctyl sulfosuccinate is recommended for use with insects which are hard to control such as red spider, cochineal, nematod, which have advantages such as dissolution and thinning of the protective layer on harmful insects and allowing the pesticides to work easily due to its chitin dissolution property. It has been reported that the surface tension values of mixtures with a concentration of $2 \%$ and above are measured as low as $27 \mathrm{mN} \mathrm{m}^{-1}$ in the studies with different trademarked surface active substances carrying sodium dioctyl sulfosuccinate as the active ingredient [28]. In this study, the surface tension was measured by preparing a mixture according to the $0.5 \mathrm{~mL} . \mathrm{L}^{-1}$ dose indicated on the label of the surfactant $\mathrm{E}$. According to other researches, it can be said that keeping the dosage lowered causes the surface tension to rise to a higher value. 
Table 2. Surface tension values of spreader-adhesives and changes in surface tensions

\begin{tabular}{|c|c|c|c|}
\hline Surfactant & $\begin{array}{l}\text { Suggested Dosage } \\
{\left[\mathrm{mL} \mathrm{L}^{-1}\right]}\end{array}$ & $\begin{array}{l}\text { Product Surface Tension } \\
{\left[\mathrm{mN} \mathrm{m}^{-1}\right]}\end{array}$ & $\begin{array}{l}\text { Surface Tension in Mixture with } \\
\text { Water } \\
{\left[\mathrm{mN} \mathrm{m}^{-1}\right]}\end{array}$ \\
\hline $\bar{A}$ & 2,5 & 24,47 & $26,92^{C}$ \\
\hline B & 0,3 & 25,12 & $62,51^{\mathrm{g}}$ \\
\hline C & 0,5 & 37,04 & $73,29^{h}$ \\
\hline D & 1 & 29,29 & $49,24^{f}$ \\
\hline$E$ & 0,5 & 20,87 & $41,94^{\mathrm{e}}$ \\
\hline $\mathrm{F}$ & 0,4 & 28,17 & $25,23^{b}$ \\
\hline G & 0,2 & 24,54 & $20,21^{a}$ \\
\hline $\mathrm{H}$ & 1 & 24,53 & $73,51^{h}$ \\
\hline İ & 1 & 22,21 & $27,49^{C}$ \\
\hline J & 0,5 & 29,55 & $35,64^{d}$ \\
\hline Pure Water & - & 73,21 & - \\
\hline
\end{tabular}

The difference between the same letters in the column is insignificant at $\mathrm{P}<0.05$.

\section{Drop contact angle findings}

In Figure 1, leaf surfaces show statistically different results from each other according to the contact angles they form. According to the drop contact angle behaviours of the leaves, Citrus lemon leaf has the lowest values in terms of the contact angle formed on its surface. [29], has found a similar result related to this in his research. It can be said that Citrus lemon leaves are more hydrophilic due to the high energy they have. Citrus sinensis, Habiscus esculentus and Capsicum annum plants were analysed as plants whose data on contact angles formed on their leaves produced efficacious results on the second order. It has been determined that the values of the contact angle formed on the surface of Lycopersicon esculentum leaf are most effective on the third degree of freedom, while Vitis vinifera formed the highest contact angle on its leaf surface. It can be said that having a lower surface energy of Vitis vinifera leaves leads to formation of large contact angles. For this reason, it is understood that it shows a hydrophobic character and affects the formation of large contact angle. [7], they have found similar results in two different studies. 
As can be seen from the graph in Figure 1 , it is understood that mixtures with surfactants $G, A, I$, and $F$ that tend to stick more to the leaf surface over time among the additives exhibiting behaviours that surface active substances form on the surface of the leaves will positively affect the pesticide performance. It is known that these four additives are mixtures with the lowest surface tension. In the determination of the amount of adsorption, spreading and sticking of surfactant mixtures on different surfaces, the levels of change in the contact angles measured on the third and tenth seconds on the leaf surfaces are examined over two times interval, and average values obtained after seven seconds are given in Chart 2. Accordingly, it is understood that the mixture prepared with $\mathrm{B}, \mathrm{C}$ and $\mathrm{H}$ shows similar behaviours on different surfaces. All three surfactants are composed of active cellulosic ingredient. Furthermore, mixtures with the highest surface tension were formed with these three adjuvants. So, it is understood that such additives show negative behaviours against spreading on different surfaces for certain periods. These drops, which protect their spherical form, have been evaluated to cause flow losses by not being able to adsorb to the surface during application. It is understood that the use of such additives should be treated selectively taking into account other parameters.

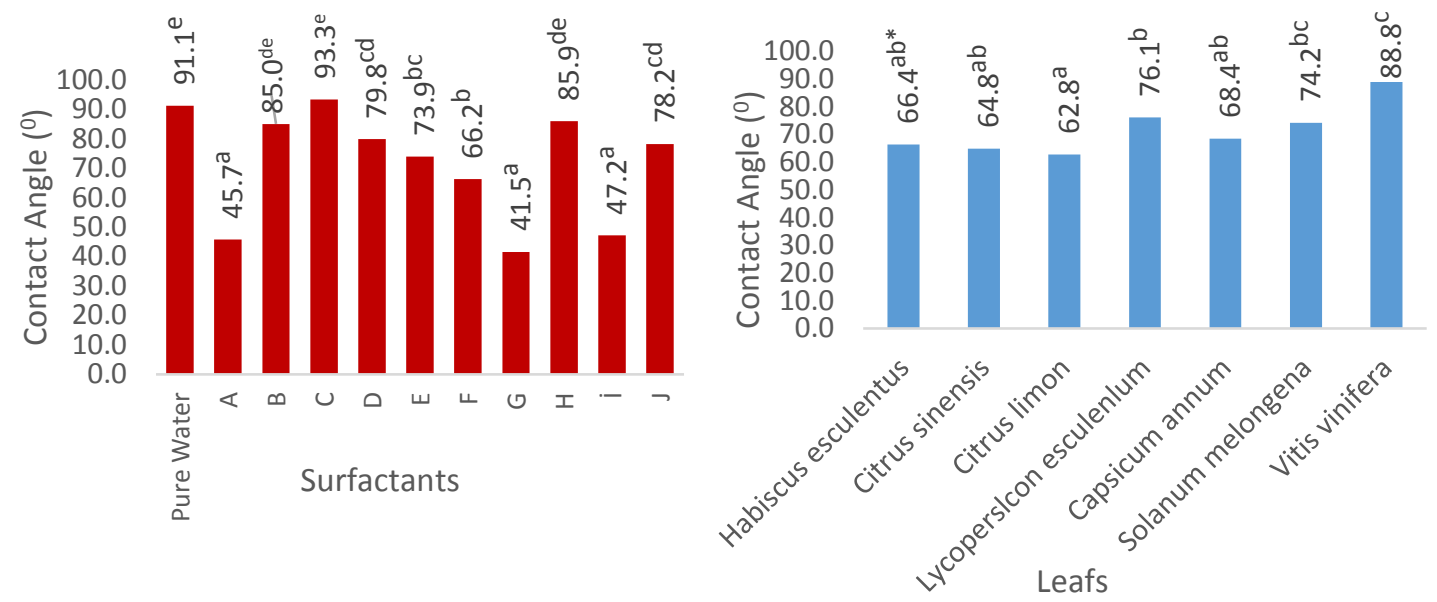

Figure 1 . On the leaf surfaces of surfactants average contact angles, they created in the 3 rd second $\left({ }^{0}\right)$.

The difference between the same letters is insignificant at $P<0.05$ level

In comparison of the averages shown in Figure 2 in terms of the leaves, the contact angle changes at the end of seven seconds of the leaf surfaces formed statistically significant differences. On the surfaces of Citrus sinensis, Vitis vinifera, Citrus lemon, there were the leaves forming the lowest angle changes. Angle formation and variation are affected at different levels by the different properties of surfaces applied. It is known that this interaction is under the influence of many factors such as the relationship between the static electric charge of the surfaces and the application liquid load, the $\mathrm{pH}$ level, the chemical structures of the surfaces and the application liquid, and the new bonds, the moisture level, the temperature, the presence of hairs on the surface, the surface roughness that occur as a result of the influence of these structures on each other. On the other hand, Solanum melongena $L$. and Habiscus esculentus leaf have formed a different group by providing more angle change. In Figure 2, although Citrus lemon and Citrus sinensis seem to give different results, it is understood 
that the leaves of these products, which are in the same family, produce approximate results.

Figure 2. Average reduction amount in angles they created in 7 seconds on the leaf surfaces of surfactants $\left({ }^{0}\right)$. The difference between the letters is insignificant at $P<0.05$ level

\section{Drop contact height findings}
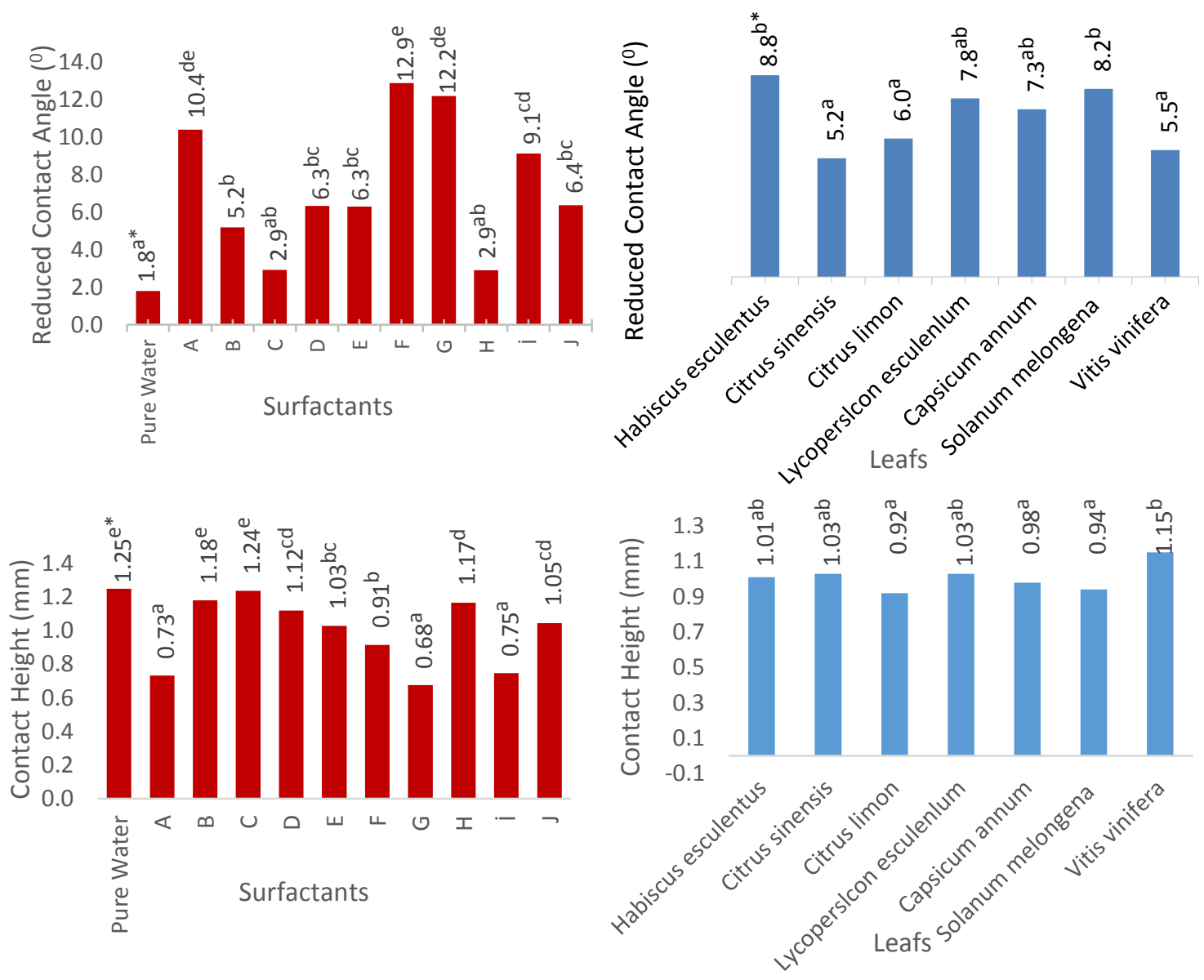

Mixtures of pure water, $\mathrm{C}, \mathrm{B}$, and $\mathrm{H}$ formed the largest contact heights created in the third second by drops on the surface of the leaves given in Figure 3. We can say that these cellulosic products, which have the highest surface tensions, both reduce adsorption, delay sticking and promote the formation of drops more prone to flow by stimulating the formation of high contact angle of the application drops on different leaf surfaces. These mixtures were followed by E and J surfactant mixtures, respectively, to obtain drop heights with intermediate values. It has been observed that these mixtures have created moderate levels of surface tension. The lowest contact heights among the surfactants were created by G, A and I surfaktants. These mixtures can be said to be the products that maximize the change of height on the leaf surfaces with the lowest surface tensions, in other words, that increase the sticking most. In Figure 3, it is observed that the drop heights formed on Vitis vinifera leaf surfaces are the greatest. It is understood that Citrus sinensis, Lycopersicon esculentum and Habiscus esculentus leaves have relatively low drop heights. The minimum drop heights were obtained on the leaf surfaces of Citrus lemon, Solanum melongena L. and Capsicum annum

Figure 3. On the leaf surfaces of surfactants average contact heights $(\mathrm{mm})$ they created in the 3rd second

The difference between the same letters is insignificant at $P<0.05$ level 
According to Figure 4, it can be seen that the $G$ and $F$ surfactants exhibit a favourable performance in terms of reduction in average contact height at the end of the tenth second. It is understood that the surfactants $A$ and $B$ also show rapid spreading and the solutions to be prepared with these surfactants will increase their effectiveness during application. It can be said that these four surfactants are the mixtures with the lowest surface tension, so they provide the lowest contact heights in the tenth second. This sequence was followed by the decreasing heights of the drops from the mixtures produced from additives $D, E$ and J. On the contrary, it has been determined that the minimum height reduction is attributed to the drops obtained from mixtures made with pure water, $\mathrm{C}$, and $\mathrm{H}$ additives. It is understood that these mixtures determine the results with the highest surface tensions. Referring to Figure 4, it was determined that the leaf surface where the droplets obtained from the mixtures prepared with surface active substance collapsed the fastest belonged to the Habiscus esculentus plant, and the Lycopersicon esculentum leaf values were observed to have the second order importance. It can be deduced that plants with such leaves have made themselves more resistant to flow by allowing drops applied during spraying to stick more quickly to their surfaces. Capsicum annum and Solanum melongena L. plants have been seen in figure to have a third-order importance in decreasing the height of the drops applied to their leaf surfaces. The decrease in drop heights on the surface of Vitis vinifera, Citrus lemon and Citrus sinensis leaves appears to be minimal.
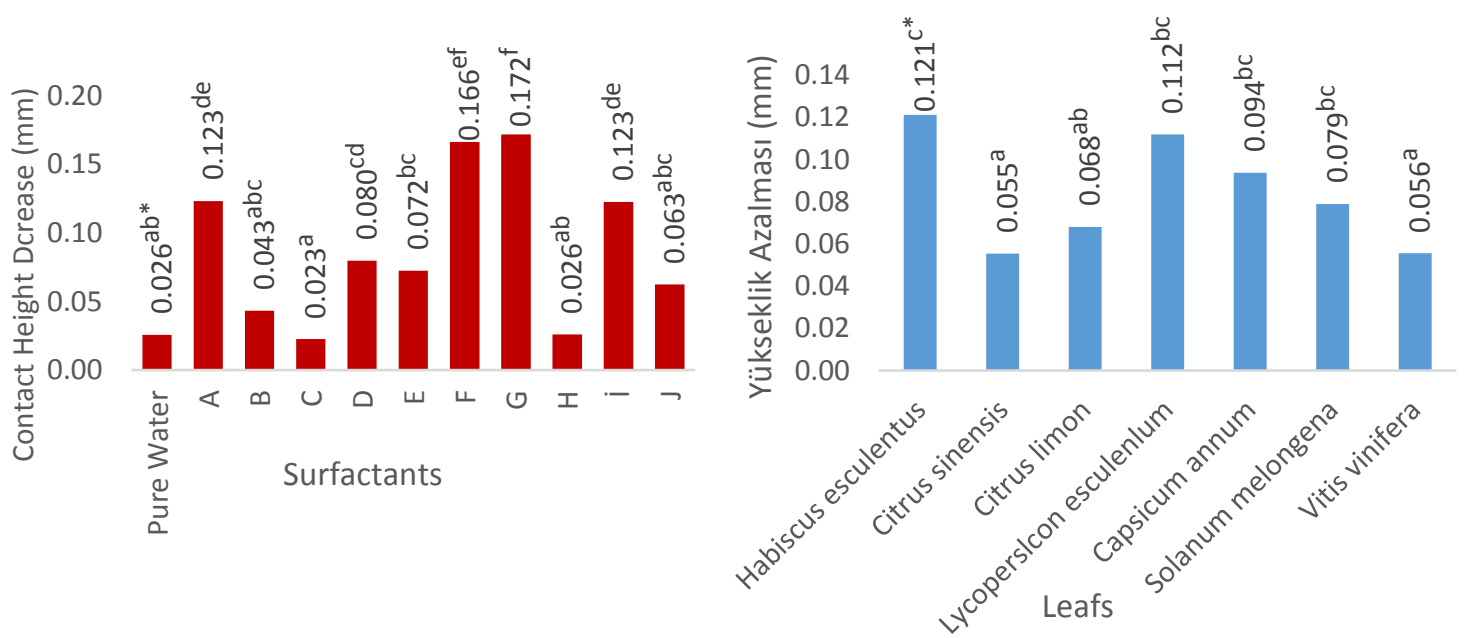

Figure 4. Decrease amounts at average contact height in 7 seconds on leaf surfaces of surfactants $(\mathrm{mm})$

The difference between the same letters is insignificant at $P<0.05$ level

\section{Drop Contact Diameter Findings}

The drop contact diameter values formed on the leaf surfaces are given in Figure 5. According to statistical analysis results in terms of contact diameter averages, it is understood that mixtures of G, A and I form the largest contact diameters and increase pesticide efficacy on the surface of leaves with a high covering area. It have been concluded that these mixtures promote the maximum spreading as being the mixtures with the lowest surface tension. It is possible to say that the drops which will be sprayed from these mixtures will immediately adsorb to the surface to be applied and spread by causing resistance against flow. When examined in this respect, these three surfactants forming the first group also show a significant difference in terms of other parameters. The additive $\mathrm{F}$ produced data close to the first group with the values of the drop diameters it formed and gave lower spreading results. The additive $C$ provided the lowest diameter formation, while the remaining $H$, Pure water, J, D, E, and B produced moderate values. 
In Figure 5, which shows the average results of the data obtained by applying ten surfactant mixed drops to each leaf, Vitis vinifera, Solanum melongena $L$. and Lycopersicon esculentum leaves formed the first group forming the minimum diameters of contact on their surfaces according to statistical analysis of the contact diameters on their leaf surfaces. It is seen that these leaves inhibit the formation of sudden diameters, but as shown in Fig. 6 , they support the maximum diameter increase over time. Although an impression such that the drops cannot hold on the surfaces of the leaves of Lycopersicon esculentum and Solanum melongena L. occurs here in terms of diameter formation at the first stage, it is actually seen that the drops applied to the surfaces are adsorbed strongly and prevented to flow, and that they provided a diameter increase by spreading the drops on them to the surface over time. Capsicum annum, Citrus lemon, Citrus sinensis leaves produced results of moderate values in terms of diameter averages. Finally, Habiscus esculentus differed by promoting the formation of the greatest contact diameters.

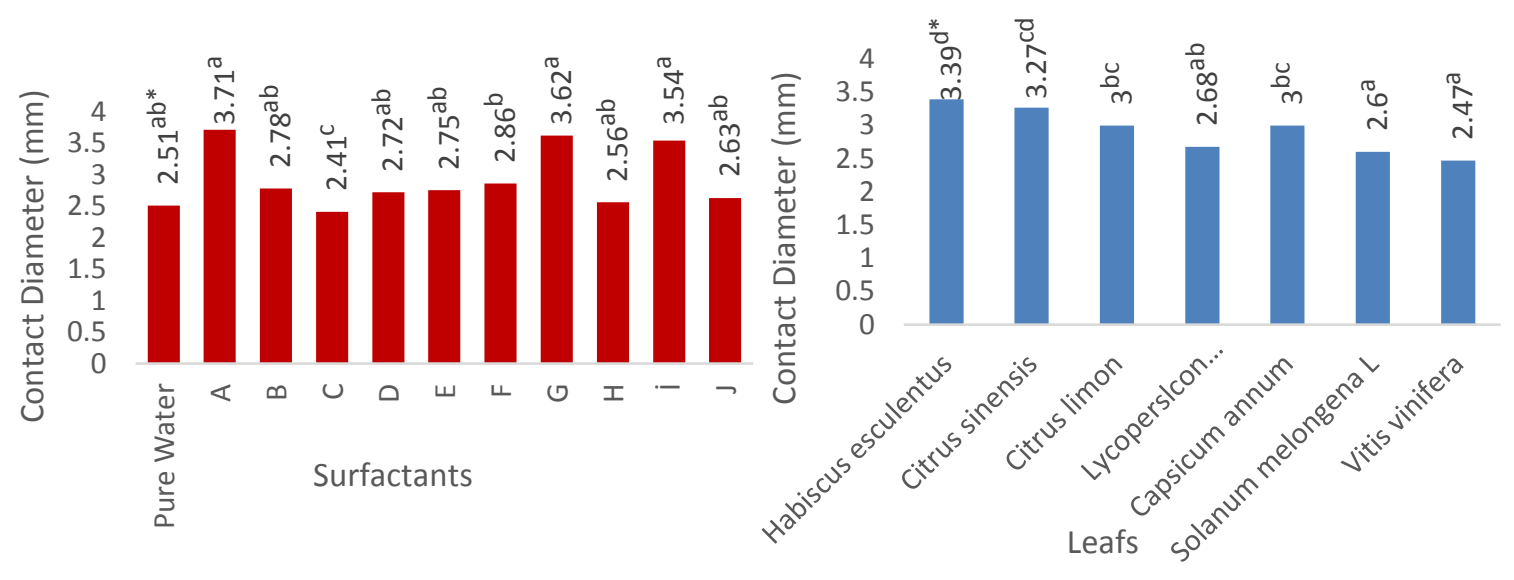

Figure 5. Average contact diameters of droplets created in the 3rd second (mm)

\section{The difference between the same letters is insignificant at $P<0.05$ level}

When the increase in the drop diameters on the leaf surfaces shown in Figure 6 is evaluated in terms of surface active materials, it has been found that the greatest increase is produced by $G, F, A$ and I mixtures. It is known that these mixtures are the products that provide the lowest surface tension. Accordingly, it can be said that the surface tensions are the determinant of the spread of the additives, which are composed of different components. These were followed by E, B, D and J additive mixtures, respectively, forming a group with other characteristics. The lowest diameter increases were obtained by pure water, $\mathrm{C}, \mathrm{H}$, and $\mathrm{B}$. It can be said that the reason for these mixtures, which are composed of the same active ingredients other than pure water, to show the minimum increase in spreading diameter on different leaf surfaces is the high surface tensions they have. in the comparison of the averages shown in Figure 6, the importance level calculated in the test of diameter increase on the leaf surfaces over time was higher than the importance level of the test. Therefore, there was no significant difference between the leaves due to the increase in diameter on the leaf surfaces after seven seconds. However, as shown in Figure 6, it was observed that the maximum diameter increase was provided by leaf surfaces of Lycopersicon esculentum, Habiscus esculentus and Solanum melongena $L$. It has been determined that the leaves of Capsicum annuum plant causes significant drop diameter increase in the second level, while the lowest drodiameter increase is obtained from leaf surfaces of Citrus lemon, Vitis vinifera and Citrus sinensis plants. 

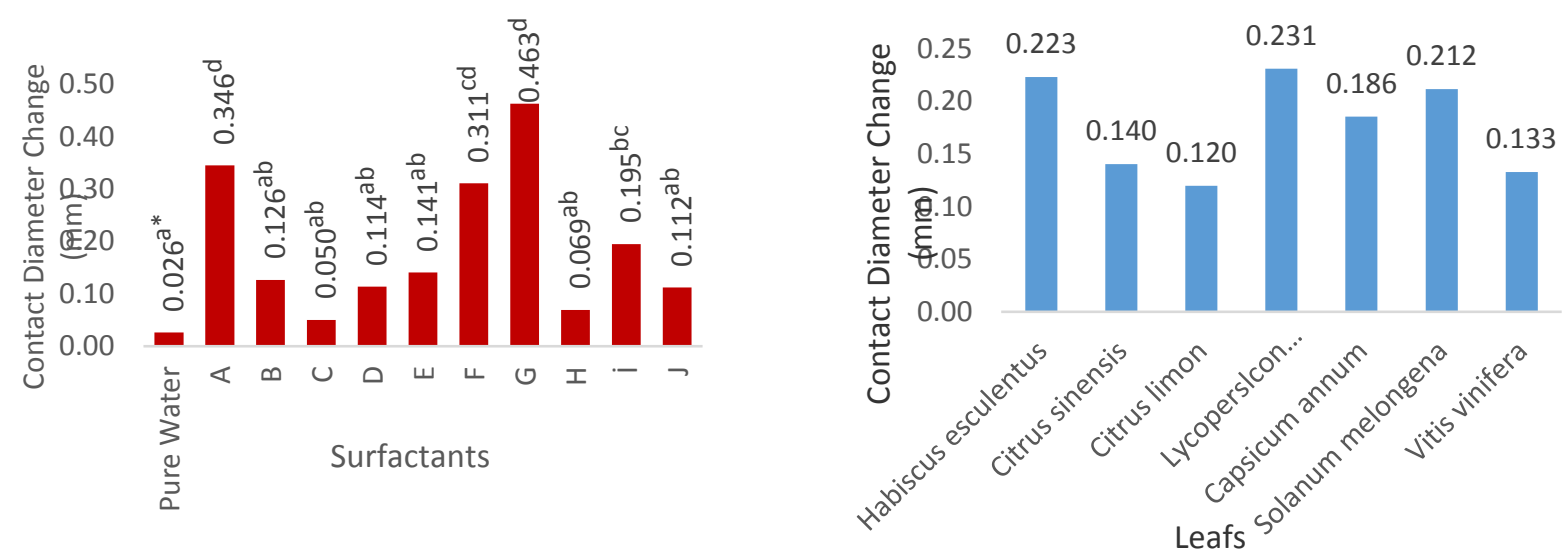

Figure 6. Amount of increase in the average contact diameters created by mixtures on leaf surfaces in 7 seconds

\section{The difference between the same letters is insignificant at $P<0.05$ level}

There is a linear relationship between the contact angle and the contact height of the droplets composed of mixtures on the leaf surfaces as shown in Figure 7. The Pearson coefficient between the drop contact angle and the drop contact height was calculated as $r=0.886$, so a strong positive relationship was deduced. A regression analysis was performed for contact angles to determine the degree of explanation of contact heights, and the $\mathrm{R}^{2}$ value was found to be 0.786 . According to the obtained $\mathrm{R}^{2}$ value, contact angles explain only $79 \%$ of the decrease of contact heights. According to this result, it has been concluded that adding contact heights as a function of time to the calculations in terms of adhesiveness is a correct approach. In order to explain the total change in drop contact heights, the resulting simple linear regression model is expressed by the equality $\hat{y}=$ $0,241+0,011 x$. The Pearson coefficient was found to be $r=-0.768$ in the relationship between contact angles and contact diameters that the mixtures formed on leaf surfaces. The $\mathrm{R}^{2}$ value in the regression analysis made was found to be 0.590 . According to the obtained value of $R^{2}$ the use of contact angles data just for determining the diameter increase on different leaf surfaces, in other words the spreading properties of the surface active substances, explains only $59 \%$ of the results obtained. Accordingly, it has been concluded that the evaluation of the drop contact diameter increase data as a function of time together with the drop contact angles for determining the effectiveness of additives is a correct method for more clear results. The equality for the simple linear regression model that is formed to explain the total change in the drop contact diameter is as follows: $\hat{y}=$ $4,675-0,025 x$.
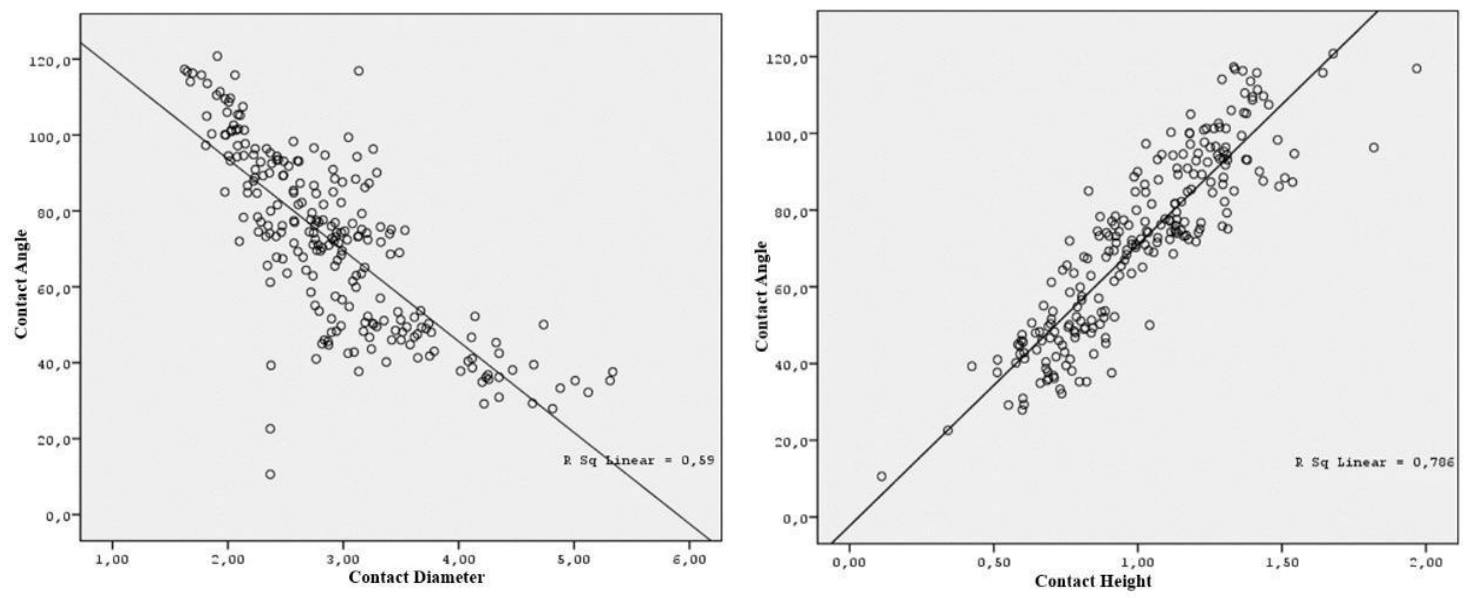
Figure 7. Relationship between contact angles with contact heights and contact diameters

\section{Conclusions}

The decisive factor on the effectiveness of surfactants is determined to be the liquid surface tensions of the mixtures prepared with them. It was found that the drops produced from $\mathrm{C}, \mathrm{B}$ and $\mathrm{H}$ surfactants tended to flow having been not able to adsorb on the leaf surfaces at the end of the third second because the averages of the contact angles they formed on the leaf surfaces were higher than $80^{\circ}$ The fact that these additives have a high surface tension and that their contents are composed of cellulose derivatives gives rise to the fact that additives with contents such as carboxymethylcellulose and sodium carboxymethylcellulose, which are widely sold in the market, do not give effective results. It has been found that the drops obtained from mixtures prepared with $G, A$ and I surfactants exhibited spreading on the surface of the leaves to form the desired angles in the agricultural struggle. It has been determined according to the literature records that these surfactants had the best results among the mixtures with surface active substances because of their alcohol content. D, E, F, and J adjuvants formed contact angles between the hydrophilic and hydrophobic regions, thus they have been classified as the category of moderate level surface active substances. The surface tension values of the surfactants at the recommended concentration should be written on their labels. Thus, producers will be able to choose the surface active substance they will buy accordingly by comparing with the surface energy value of the plant to which they will apply.

\section{References}

1. Kirkaç Ç., (2005): Evaluation of Pestisit Droplet Distribution by Image Analysis, Ankara University. Master Thesis. Ankara.

2. Çilingir İ., Dursun E. (2010): Plant Protection Machines. A.Ü. Agriculture Departmants. Publication No: 1531, Course Books Publication Number: 484 Ankara.

3. Fowkes F.M. (1964): Attractive Forces at Interfaces. Industrial and Engineering Chemistry 56 (12): 40-52.

4. Moy E., Neumann A.W. (1987): Solid/Liquid Interfacial Tensions from contact Angle Data and Direct Force Measurements. Journal of Colloid and Interface Science. 119 (1): 296-297.

5. Owens D.K., Wendt R.C. (1969): Estimation of the Surface Free Energy of Polymers. In: Journal of Applied Polymer Science 13(8): 1741-1747.

6. Zisman W.A. (1964): Relation of Equilibrium Contact Angle to Liquid and Solid Constitutions in Contact Angle, Wettability and Adhesion. Advances in Chemistry Series. American Chemical Society: Washington D.C., Vol.43, 1-51.

7. Gaskin R.E., Steele K.D., Forster W.A. (2005): Plant Protection Chemistry. New Zealand.

8. Hock W.K. (1998): Horticultural Spray Adjuvants. The Pennsylvania State University, 112 Agricultural Administration Building, U.S. University Park, PA 16802.

9. Tu M., Randall J.M. (2001): Adjuvants, 8.1-8.24. In Weed Control Methods Handbook: Tools and Techniques for Use in Natural Areas (Eds: M. Tu, C. Hurd \& J. M. Randall). The Nature Conservancy, The Global Invasive Species Team.

10. Holloway P.J., Silcox D. (1985): Behaviour of Three Nonionic Surfactants Following Foliar Application. 1985 British Crop Protection Conference-Weeds. BCPC Publications, Croydon, UK.

11. Zabkiewicz J.A., Gaskin R.E., Balneaves J.M. (1985): Effect of additives on foliar wetting and uptake of glyphosate into gorse (Ulex europaeus). 1985 BCPC Monogram No. 28 Symposium on Application and Biology. 
12. Holloway P.J., Wong W.W.C., Partridge H.J. (1992): Effects of some nonionic polyoxyethylene surfactants on uptake of ethirimol and diclobutrazol from suspension formulations applied to wheat leaves. Pesticide Science, 34, 109-118.

13. Uhlig B.A., Wissemeier A.H. (2000): Reduction of nonionic surfactant phytotoxicity by divalent cations. Crop Protection, 19, 13-19.

14. Brazee R.D., Bukovac M.J., Zhu H. (2004): Diffusion model for plant cuticular penetration by a spray applied weak organic acid bioregulator in presence or absence of ammonium nitrate. Transactions of the ASAE, 47(3), 629-635.

15. Ellis M.C.B., Tuck C.R., Miller P.C.H. (2001): How surface tension of surfactant solutions influences the characteristics of sprays produced by hydraulic nozzles used for pesticide application. Colloids and Surfaces A: Physicochemical and Engineering Aspects, 180, 267-276.

16. Ramsdale B.K., Messersmith C.G. (2001): Nozzle, spray volume, and adjuvants effects on carfentrazone and imazamox efficacy. Weed Technology, 15, 485-491.

17. Stainier C., Destain M.F., Schiffers B., Lebeau F. (2006): Droplet size spectra and drift effect of two phenmedipham formulations and four adjuvants mixtures. Crop Protection, 25, 1238-1243.

18. Spanoghe P., Schampheleire M.D., Meeren P.V.D., Steurbaut W.(2007): Influence of agricultural adjuvants on droplet spectra. Pest Management Science, 63, 4-16.

19. Stevens P.J.G., Walker J.T.S., Shaw P.W., Suckling D.M. (1994): Organosilicone surfactants: tools for horticultural crop protection. Proc. Brighton Crop Prot. 755-760.

20. Zabkiewicz J.A., Coupland D., Ede F. (1988): Effects of surfactants on droplet spreading and drying rates in relation to foliar uptake. Pesticide Formulations 77-89.

21. Nalewaja J.D., Matysiak R. (2000): Spray deposits from nicosulfuron with salts that affect efficacy. Weed Technology 14: 740-749.

22. Basu S., Luthra J., Nigam K.D.P. (2002): The effects of surfactants on adhesion, spreading and retention of herbicide droplet on the surface of the leaves and seeds. Journal of Environmental Science and Health, B37(4), 331- 344.

23. Gaskin R.E., Murray R.J., Krishna H., Carpenter A. (2000): Effect of adjuvants on the retention of insecticide spray on cucumber and pea foliage. New Zealand Plant Protection. 53, 355-359

24. Camacho F.G., Grima E.M., Miron A. S., Pascual V.G., Chisti Y. (2001): Carboxymethyl cellulose protects algal cells against hydrodynamic stress. Department of Chemical Engineering, University of Almería, E-04071 Almerı́a, Spain. Enzyme and Microbial Technology 29. 602-610.

25. Hoffman B.J. (2004): Analysis of Alcohol and Alkylphenol Polyethers via Packed Column Supercritical Fluid Chromatography. Doctor of Philosophy in Chemistry. Blacksburg, Virginia.

26. Kural F.H., Gürsoy R.N. (2011): Biosurfactants. Journal of Hacettepe University Faculty of Pharmacy. Volume 31, Issue 1, pp. 71-82.

27. Biscay F., Ghoufi A., Malfryt P. (2011): Surface tension of water-alcohol mixtures from Monte Carlo simulations. The Journal of Chemıcal Physics 134, 044709.

28. Cytec (2013): Specialty Additives Aerosol Surfactants. Aerosol Surfactants Brochure.

29. Temeldaş M. (2007): Evaluation of Spreader-Adhesives Participating in Agricultural pesticides in terms of Spraying Technique. Cukurova University. Adana. 